\title{
Method and Approaches to the Estimation of Ecological Risks of Urban Territories
}

\author{
Andrey V. Vasilyev, Samara State Technical University
}

\begin{abstract}
Negative environmental factors (chemical, physical, biological) may cause significant negative influence both over environment and the health of the population. Maximal number of sources of negative impact is located in industrial regions. Factors and existing methods of the estimation of ecological risks of urban territories are discussed. The main steps of estimation of ecological risks of urban territories are described. New approaches to estimation of ecological risks of urban territories are suggested. Program provision has been developed for the estimation of ecological risks allowing to forecast the level of pollutions of the environment of urban territories. The results of approbation of the new method and program provision of estimation of ecological risks on the example of the territory of Samara region of Russia have been described.
\end{abstract}

Keywords - Ecological risk, estimation, impact, method, urban territory.

\section{INTRODUCTION}

Presently, in the conditions of a modern city it is possible to point out many negative factors of impact on environment. Among them are chemical, physical, biological factors. Impact of such factors may cause risks of negative sequences both to environment and to the health of the population.

Ecological risk may be considered as deviation from generally admitted principles and norms of relations of man, business subjects, society and state with the surrounding environment and from the norms of social relations between them.

To efficiently reduce ecological risk and decide about the possibility of reduction of negative impact of different factors up to the certain limits, it is necessary to carry out forecasting and estimation of ecological risks.

Maximal number of anthropogenic sources of ecological risks is situated in industrial regions including clusters of industrial, domestic and agriculture zones [1-7, 12].

This paper is devoted to the study and development of new methods and approaches and program provision for the estimation of ecological risks in the conditions of urban territories.

\section{NEW METHOD AND APPROACHES TO ESTIMATION OF ECOLOGICAL RISKS OF URBAN TERRITORIES}

Method of estimation of ecological risks of urban territories (including estimation of the influence of different types of pollution on the health of the population) may be subdivided into different steps:

- identification of the ecological danger of the sources and objects of urban territory;
- analysis of inhabitant complaints regarding negative pollution disturbance;

- analysis of population sick rate in the database of Russian medical institutions (polyclinics, hospitals, etc) for the certain territories;

- development of integral generalized criteria of ecological dander of the objects;

- selection and application of an adequate mathematicstatistical method of analysis and generalization of the experimental data:

- inhabitant self-assessment of the health state depending on the conditions of protection from pollution disturbance, etc.

Estimation of ecological risks may include different steps: identification and estimation of probability of occurrence of events having negative sequences for the environmental state, health of the population, violation of ecological requirements, emergency situations caused by natural and anthropogenic reasons, etc.

In order to estimate ecological risks of a territory more precisely, it is necessary to develop approaches and program provisions for the estimation of ecological risks.

The criteria to determine the risk of physical pollutions damage to the population health are shown in Table I.

TABLE I

Ceiling Sound Levels (DB) FOR DifFerent Kinds of Population ACTIVITY FOR DIFFERENT CLASSES OF CONDITIONS (DEGREES OF RISK)

\begin{tabular}{|l|l|l|l|l|}
\hline $\begin{array}{l}\text { The kinds } \\
\text { of activity } \\
\text { during the } \\
\text { 24 hours }\end{array}$ & $\begin{array}{l}\text { Optimal } \\
\text { condition } \\
\text { s(risk is } \\
\text { absent) }\end{array}$ & $\begin{array}{l}\text { Admissible } \\
\text { conditions } \\
\text { (negligible } \\
\text { risk) }\end{array}$ & $\begin{array}{l}\text { Harmful } \\
\text { conditions (risk } \\
\text { endurable with } \\
\text { protective } \\
\text { measures) }\end{array}$ & $\begin{array}{l}\text { Damage } \\
\text { conditions } \\
\text { (unaccepta } \\
\text { ble risk) }\end{array}$ \\
\hline Sleeping & 15 & 30 & 45 & 60 \\
\hline Rest & 35 & 50 & 65 & 80 \\
\hline Work & 50 & 80 & 100 & 110 \\
\hline
\end{tabular}

Traditional approach using multi-factor dispersion analysis and Fisher's F-criterion for the estimation of importance of separate factors and their combinations do not allow solving the task of forecasting the functional state of man (FSM) by using the values of parameters of external medium and other factors, participating in its formation. In this case, it is necessary to use a number of regressive models, describing the interrelation of separate indicators of the functional state of man with linear or non-linear combination of factors of external environment (FEE). A number of such equations (in dependence of the number of FSM indicators used) may be rather high, and this makes its practical usage difficult. Such approach is not completely adequate. The most logical 
approach is to study a multidimensional system by multidimensional mathematical methods.

It is necessary to use the methodology of solution of system tasks with consideration of the main peculiarities of medicalbiological information, which is an adequate means of generalization and structuring of medical information in the applied medical-biological researches.

Statistical concept, including successive application of factor methods, canonical, correlation, cluster and component analysis allow to synthesize the criteria and algorithms of decisions making during the estimation of functional state of man in the applied medical-biological researches. Criteria and algorithms of the estimation of the functional state of man allow carrying out the estimation of the degree of effort associated with the mechanisms of adaptation of organism to the factors of vital activity.

It is necessary to point out that the combined impact of different factors may cause different effect on the man's organism. Damaging impact may be summated, attenuated or amplified, as well as may cause variation of the character of influence $[1,6,7,10]$. Therefore, for the adequate estimation of the effects of negative impact of damaging environmental factors it is necessary to carry out the analysis and account of different situations of impact of different combinations of ecological factors.

New approach to determine the integral indicator of functional state of man (FSM) in coincidence with integral indicator of physical factor of environment (PFE) may be carried out on the basis of interrelation of one-dimensional multi-parametric characteristic of system response of organism $\left(L_{\text {sost }}\right)$ and one-dimensional multi-parametric characteristic of external environment $\left(L_{\mathrm{sr}}\right)$. In this case $L_{\mathrm{sost}}=L_{\mathrm{sr}}$. On the basis of the application of canonical correlation analysis, it is determined that there is a close interrelation of the totality of indicators of FSM with the totality of parameters of external environment $(\rho=0.82 ; p<0.05)$.

During estimation of ecological risks it is also necessary to consider the effect of summation (addition of small quantities of different damaging substances). Such quantities of substances separately may do not cause any problems for health or the ecosystem, but in sum they become dangerous due to the mutual amplification of effects (synergetic impact) [6, 8, 9-11].

It is important to note that it is also possible to use summation principle during calculation of complex impact of polluting substances on the man, penetrating into man's organism with air, water and food.

\section{DEVELOPMENT OF PROGRAM PROVISION FOR ESTIMATION OF ECOLOGICAL RISKS}

Program provisions for the estimation of ecological risks have been developed. It allows carrying out complex estimation of risks and estimating joint impact of main chemical and physical factors on the human organism taking to account possible toxic effects. Program provision also allows carrying out automatic processing and estimation of results of measurements of different physical and chemical pollutions and making calculations of integral values of impact of factors of different nature.

Program provision "Integrated monitoring of physical and chemical pollutions" (IMCF) consists of 3 main blocks integrated with other modules of the automated working place "Complex City Test":

1. Informational block including:

- databases of physical factors and chemical pollutants of the environment of urban territories (air, water, soil);

- informational-reference tables of values of maximal admissible concentrations and maximal admissible levels of main chemical pollutants and of physical factors;

- lists of the main chemical toxicants and physical pollutions of town;

- lists of the main sources and factors of chemical and physical impact on the population;

- information databases of medical statistics, databases of ecologically caused illnesses of the citizens.

2. Program-analytical block containing:

- module of automated processing of measurement results of different chemical and physical impacts;

- module of ecological-toxicological estimation of measurements allowing carrying out estimation of the correspondence of measurement results to the sanitaryhygienic requirements;

- module of integral estimation and analysis of the combined impact of factors of different nature allowing to carry out integral estimation of joint impact of physical and chemical factors on the human health, calculation of ecological risks and integral values of physical and chemical pollutions of environment taking into account indexes of toxic effects of synergetic impacts exceeding the effects of summation.

3. Block of mapping of territory (GIS-mapping) containing:

- module of mapping of territory of town for different pollutants and factors of physical impact;

- module of dynamic mapping of physical fields and chemical pollutions of town;

- module of mapping of integral impact of limiting factors allowing to create maps according to the results of measurements and calculations of integral values of the combined impact of factors of different nature, dynamic maps of physical and chemical pollutions (maps of ecological risks, maps of combined impact of factors).

Results of calculations depending on the number of values may be presented either as a table of measurements or as a separate field of results displaced below the table of measurements.

Program allows to input into the database the results of measurements of the following impacts: noise (sound); infrasound; ultrasound; vibration; electromagnetic field, ionizing radiation; heat radiation; chemical pollutants; main toxicants.

Automated functions of the developed program provision:

- account of measurements of concentrations of chemical components for inhalation input (atmosphere air);

- account of measurements of concentrations of chemical components for mouth input (water, food); 
- account of measurements of levels of impact of physical factors;

- storage of data about maximal admissible concentrations of chemical substances and groups of summation;

- account of data of sources of pollutant emission into the atmosphere;

- modeling of pollutant dispersion in the atmosphere air;

- calculation of ecological risk on the basis of the calculated data of ground level concentration of pollutants in the atmosphere air during gas-air mixture exhaust from a single source;

- calculation of ecological risk on the basis of measurements of concentrations of chemical pollutants;

- calculation of ecological risk on the basis of measurements of levels of impact of physical pollutions;

- complex estimation of ecological risk of impact of chemical and physical factors during the combined impact;

- determination of probability of development of cancer illnesses.

The graphical two-dimensional map of investigated territory is used as the basis for mapping.

Program provision allows determining the most dangerous zones of urban territory with regard to the probability of develiopment of chronic illnesses from complex influence of chemical and physical factors (Fig. 1).

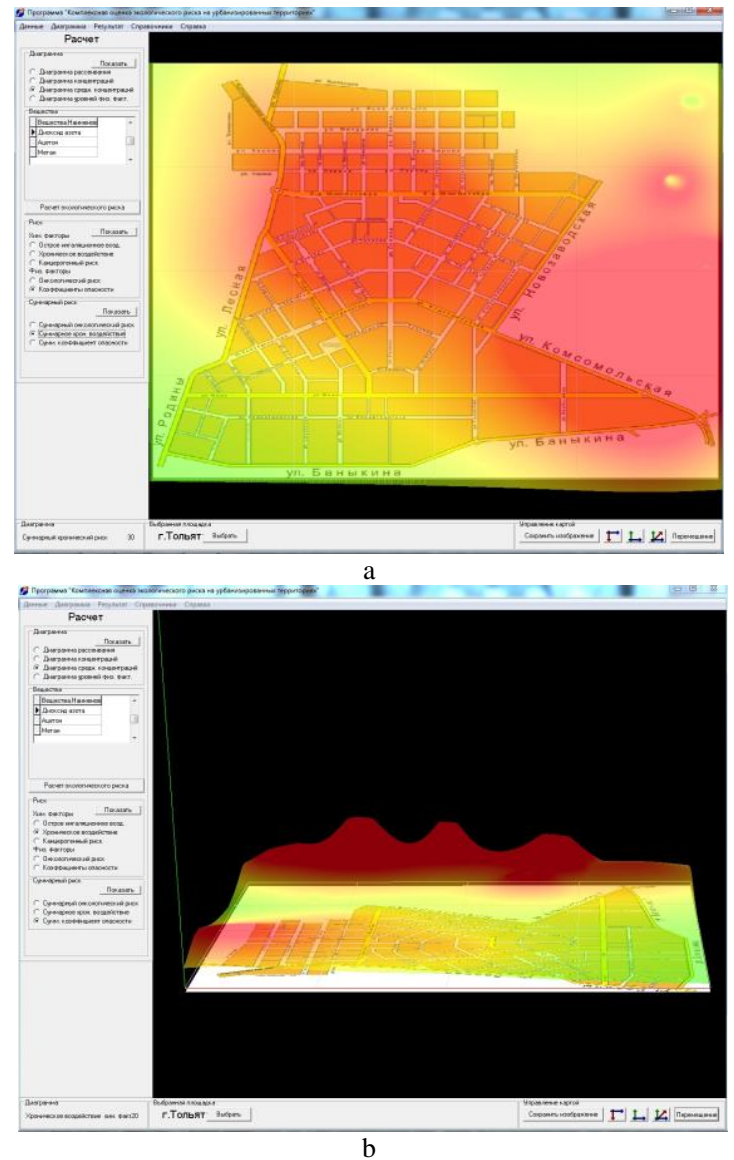

Fig. 1. Two-dimensional (a) and three-dimensional (b) representation of results of estimation of ecological risk using the developed program provision.

\section{EXPERIENCE OF APPROBATION OF NEW METHODS AND PROGRAM PROVISION FOR ESTIMATION OF ECOLOGICAL RISKS IN CONDITIONS OF URBAN TERRITORIES}

New method and program provision have been approbated for the complex research and estimation of ecological risk in conditions of Samara Region. The following components were determined as the main pollutants: formaldehyde, dioxide of nitrogen, dioxide of sulfur, oxide of carbon, methane, acetone, sterol, benzopyrene. Together with the estimation of chemical pollution, the analysis of influence of the following physical factors was carried out: noise, vibration, ionizing radiations, electromagnetic fields of industrial and radio frequency range, radon.

Application of the automated system allowed obtaining the data of probabilistic development of different illnesses depending on the factors of impact (Fig. 2 a - chemical factors; $\mathrm{b}$ - physical factors) and point them out in the map of the territory.
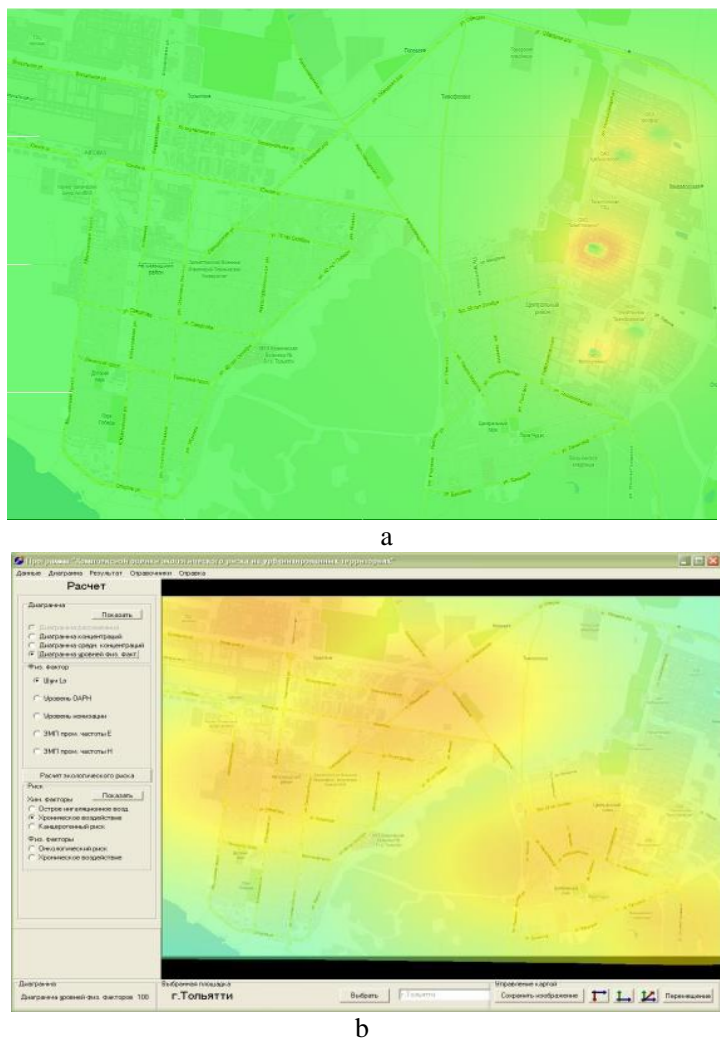

Fig. 2. Example of calculation of probabilistic development of different illnesses depending on the factors of impact.

a - acute inhalation impact of chemical substances;

$\mathrm{b}$ - probability of development of chronic illnesses from noise impact.

The developed program provision allows not only to receive the data about the probability of the development of different illnesses from the main chemical, physical and biological factors, but also to estimate their integral impact taking to account synergism effects. 


\section{CONCLUSION}

New methods and approaches to estimation of ecological risks of urban territories are allowing to consider joint impact of physical and chemical pollutions and to determine the most problematic zones of urban territories.

It has been shown that complex estimation of risks is a prospective approach to efficient control of the environment quality and estimation of ecological safety.

The developed program provision allows carrying out not only separate, but also combined estimation of ecological risks of territories and to efficiently forecast the risks of ecologically caused illnesses form complex impact of factors of different nature.

The results of approbation of new approaches to estimation of ecological risks and of program provision on the example of the territory of Samara Region of Russia show high efficiency of the estimation of ecological risks of urban territories.

In total, the results of the work allow to forecast and to reduce efficiently negative impact of the environmental factors from different sources over the human health and the environment and thus to reduce ecological risks of territories.

\section{ACKNOWLEDGMENT}

The research results described in this paper were received under support of the Ministry of Education and Science of the Russian Federation in framework of the program of the state task to universities, project: "Development of resources-saving technologies of utilization of industrial and domestic waste." Project code 2006.

\section{REFERENCES}

[1] U. S. Karabanov, V. M. Chiznikova, Ecology and management: Book for universities. Moscow: MISIS, 2006, p. 712.

[2] A. V. Vasilyev, "Green politics: problems and structure," "Pro et Contra” Journal, 2002. vol. 7, no. 1, pp. 84-93.

[3] A. V. Vasilyev, Ecological Monitoring of Physical Pollutions on the Territory of Samara Region. Reduction of Impact of Sources of Physical Pollutions, Edition of Samara Scientific Center of Russian Academy of Science, Samara, Russia, 2009. p. 140, 36 ill. ISBN 978-5-93424-467-6.

[4] A. V. Vasilyev, V. O. Bukhnov, V. A. Vasilyev, "Approaches to Environmental Impact Assessment of Physical Pollutions of Territories
During Design and Construction of Industrial Objects and it Realization in Samara Region of Russia," Proc. of the International Scientific Conference (XI International Forum) Heritage. Architecture. Landesign Focus on Conservation, Regeneration, Innovation "Le vie dei Mercanti”, June 13-15, 2013, Naples, Italy, pp. 1183-1190.

[5] S. Luzzi, A. V. Vasilyev. "A Comparison of Noise Mapping Methods in Italian and Russian Experiences," Proc. of International Scientific Conference "Forum Acusticum-2005”, Budapest, Hungary, Aug. 29Sep. 2, 2005, pp. 1051-1056.

[6] R. F. Afanasyeva, G. A. Suvorov, A. G. Antonov, A. F. Bobrov, T. K. Loskin, S. N. Sokolov, "Forecasting of Heat State of Man During Impact of Complex of Factors," Medicine of Labour and Industrial Ecology, no. 2, 2000, p. 9.

[7] A. V. Vasilyev, G. S. Rozenberg. "Monitoring of Noise Pollution in Living Area of Togliatti City and Estimation of It Influence to the Health of Inhabitants," Safety in Technosphere, no. 3, 2007, pp. 9-12.

[8] S. Manahan. Environmental Chemistry, NY: Lewis Publishers, 1994. p. 789.

[9] A. V. Vasilyev. "Research of toxicity of organic waste on the territory of former "Phosphorus" company," Proc. of the 4th International Environmental Congress (6th International Scientific-Technical Conference) "Ecology and Life Protection of Industrial-Transport Complexes," ELPIT-2013, Sep. 18-22, 2013, Togliatti - Samara, Russia, pp. 46-51.

[10] A. V. Vasilyev, V. V. Zabolotskikh, "Development and Realization of Methods of Separate and Joint Monitoring of Physical Pollutions of Urban Territories," The Bulleting of Samara Scientific Center of Russian Academy of Sciences, Samara, 2013, vol. 15, no. 3(7), pp. 2354-2361.

[11] A. V. Vasilyev, V. V. Zabolotskikh., V. A. Vasilyev, "Development of Methods of Estimation of Physical Factors Impact to the Health of Population," Safety of Technogenic Environment, Riga Technical University, Riga, Latvia, 2013, vol. 4, pp. 42-45.

[12] D. Wicklum, W. Daries, "Ecosystem health and integrity?" Can. J. Bot., 1995, no. 73, pp. 997-1000.

Andrey V. Vasilyev received the Doctor of Technical Science degree in 2006. Since 2006 he has been a Professor with the Department of Chemical Technology and Industrial Ecology of Samara State Technical University. He is Head of the leading scientific school of Russia in the field of engineering ecology, ecological monitoring and of complex problems of machinery honored by the grant of president of Russian Federation. He is the author of more than 600 scientific papers and 7 books and 12 inventions. His major field of research is engineering ecology, ecological monitoring, reduction of environmental pollution.

Presently he is Head of Department of Chemical Technology and Industrial Ecology of Samara State Technical University, Head of R \& D Laboratory of Vibration, Acoustics, Ecology and Life Protection of Togliatti State University, Russia.

$\mathrm{He}$ is a Grant-holder of the German Academic Exchange Service (DAAD), Open World program of USA, field "Environment" (2004) etc.

Address: Samara State Technical University, Molodogvardeyskaya Street 244, Samara, 443100, Russia.

Phone: +7(846)242-11-76. Fax: +7(846)278-44-00.

E-mail: avassi162@mail.ru; ecology@samgtu.ru 